(c) American Dairy Science Association, 2005.

\title{
Validation of a Rapid Milk Fat Separation Method to Determine the Fatty Acid Profile by Gas Chromatography
}

\author{
P. Luna, M. Juárez, and M. A. de la Fuente \\ Instituto del Frío (CSIC), José Antonio Novais 10, Ciudad Universitaria s/n. 28040 Madrid, Spain
}

\begin{abstract}
An improved rapid method for separating lipids from milk to determine the fatty acid composition using 2 centrifugations at room temperature $\left(20^{\circ} \mathrm{C}\right)$ was compared with the ISO-IDF reference procedure based on solvent extraction. The new method is useful for research and routine quality control and has a number of advantages over the reference procedure-mainly no solvents are required and it saves time. Applicability of the rapid separation method was confirmed in fats with different physical characteristics from ewe and goat milk samples. Minor differences were found in the proportions of some fatty acids in the reference and centrifugation methods. Milk fat separated by centrifugation at room temperature did not differ in fatty acid composition from milk centrifuged at $4^{\circ} \mathrm{C}$.
\end{abstract}

(Key words: fatty acid, separation, milk fat, ewe)

\section{INTRODUCTION}

The fatty acid composition of milk fat determined by gas chromatography with capillary columns has been studied for many decades and is still highly relevant for dairy research and authentication studies. Milk fatty acid analysis presents some complexity due to the wide range of the molecular size and the presence of relatively large quantities of short-chain fatty acids. Although the problem of converting milk fatty acids to methyl esters to be analyzed by gas chromatography has been solved with the reference rapid methylation procedure (ISO-IDF, 2002), the problem of milk fat separation remains for analyzing a large number of samples.

The most widely used techniques, such as the RöseGottlieb procedure, for milk fat separation are primarily based on extraction with solvents. In the reference procedure (ISO-IDF, 2001), lipids are extracted using

Received June 2, 2005.

Accepted July 2, 2005.

Corresponding author: Miguel Angel de la Fuente; e-mail: ifraf91@ if.csic.es. a mixture of diethyl ether and n-pentane after first adding an ammonium hydroxide solution. However, these extraction methods are lengthy, requiring a lot of time to analyze just a few samples. Methods based on centrifugation (Sukhija and Palmquist, 1988; Fontecha et al., 1998) are not sufficiently standardized, and include a step to remove water with anhydrous sodium sulfate or use solvents to wash the fat. The idea of using the centrifuge for qualitative and quantitative milk fat determinations is not new and it was primarily applied in human milk studies (Lucas et al., 1978; Verheul et al., 1986).

Thus, there is a need for a rapid, reliable, and simple milk fat separation method that could be used to analyze a large number of samples in the quality control laboratory or in the research field. Feng et al. (2004) recently developed an approach suitable for this purpose, in which fat is separated by a nonsolvent method using only 2 centrifugations. This procedure was compared with a method based on extraction with a mixture of hexane:isopropanol proposed by Hara and Radin (1978) for lipid extraction from animal tissues. Although losses of phospholipids could take place (Feng et al., 2004), this method seems to be successful for determining the fatty acid profile in cow milk fat.

The aim of this study was to compare the new rapid nonsolvent separation method (Feng et al., 2004) with the official reference procedure (ISO-IDF, 2001) to determine fatty acid composition. To test the method applicability, ewe's and goat's milk with different fat contents and fat globule size were examined. Moreover, to improve this new technique, milk fat separation was assayed by centrifugation at room temperature.

\section{MATERIALS AND METHODS}

\section{Samples}

Ewe and goat milk samples were collected from different farms located in different regions of Spain to ensure a variety of milk compositions. Samples were taken from the storage tanks containing milk from the whole herd. Freshly drawn milks were shipped to the laboratory in isothermal containers. Six milk samples (3 from ewes and 3 from goats) were collected. Total fat contents 
Table 1. Mean values and standard error of the mean (\% of total fatty acids) of fatty acid methyl esters of ewes' milk determined by gas chromatography after fat separation by the reference method (ISO-IDF) and an alternative procedure based on double centrifugation. ${ }^{1}$

\begin{tabular}{|c|c|c|c|c|c|}
\hline \multirow[b]{2}{*}{ Fatty acids } & \multicolumn{2}{|c|}{ Reference method } & \multicolumn{2}{|c|}{$\begin{array}{l}\text { Double centrifugation } \\
\text { method }\end{array}$} & \multirow{2}{*}{$\begin{array}{l}\text { Statistical } \\
\text { significance }\end{array}$} \\
\hline & Mean & SEM & Mean & SEM & \\
\hline C4 & 3.546 & 0.074 & 3.675 & 0.085 & NS \\
\hline $\mathrm{C} 6$ & 2.943 & 0.085 & 3.058 & 0.088 & NS \\
\hline C8 & 2.661 & 0.089 & 2.733 & 0.085 & NS \\
\hline C10 & 7.819 & 0.281 & 7.941 & 0.262 & NS \\
\hline C10:1 & 0.323 & 0.018 & 0.325 & 0.017 & NS \\
\hline C12 & 4.174 & 0.122 & 4.175 & 0.110 & NS \\
\hline anteiso $\mathrm{C} 13$ & 0.039 & 0.002 & 0.040 & 0.002 & NS \\
\hline C13 & 0.178 & 0.006 & 0.178 & 0.005 & NS \\
\hline isoC14 & 0.104 & 0.010 & 0.106 & 0.011 & NS \\
\hline C14 & 9.827 & 0.172 & 9.730 & 0.170 & NS \\
\hline isoC15 & 0.204 & 0.013 & 0.208 & 0.012 & NS \\
\hline anteisoC15 & 0.379 & 0.013 & 0.389 & 0.013 & NS \\
\hline C15 & 0.880 & 0.016 & 0.866 & 0.017 & NS \\
\hline C14:1 & 0.153 & 0.005 & 0.157 & 0.005 & NS \\
\hline isoC16 & 0.272 & 0.010 & 0.271 & 0.010 & NS \\
\hline C16 & 26.018 & 0.142 & 25.449 & 0.166 & $*$ \\
\hline isoC17 & 0.467 & 0.007 & 0.460 & 0.007 & NS \\
\hline anteiso $\mathrm{C} 17$ & 0.243 & 0.009 & 0.247 & 0.009 & NS \\
\hline C16:1 & 1.264 & 0.019 & 1.288 & 0.018 & NS \\
\hline C17 & 0.651 & 0.019 & 0.632 & 0.017 & NS \\
\hline C17:1 & 0.184 & 0.008 & 0.191 & 0.008 & NS \\
\hline C18 & 10.520 & 0.601 & 9.961 & 0.521 & NS \\
\hline C18:1 (4-11 trans) & 2.775 & 0.263 & 2.778 & 0.267 & NS \\
\hline C18:1 cis-9 & 19.410 & 0.284 & 20.068 & 0.327 & NS \\
\hline C18:1 (other) & 0.851 & 0.025 & 0.843 & 0.028 & NS \\
\hline C18:2 (other) & 0.400 & 0.021 & 0.406 & 0.024 & NS \\
\hline C18:2 cis-9,cis-12 & 2.579 & 0.127 & 2.666 & 0.146 & NS \\
\hline C20 & 0.217 & 0.013 & 0.200 & 0.013 & NS \\
\hline C18:3 & 0.318 & 0.018 & 0.329 & 0.021 & NS \\
\hline C18:2 cis-9,trans-11 & 0.603 & 0.038 & 0.622 & 0.038 & NS \\
\hline
\end{tabular}

\footnotetext{
${ }^{1}$ Each separation method was repeated 4 times and 2 column injections per separation were carried out for each of the 3 ewe milk samples.
}

${ }^{2} \mathrm{NS}=$ Not significant, $* P<0.05$.

were 4.8 to $8.6 \%$ and 4.2 to $5.9 \%$ in ewe and goat milk samples, respectively.

\section{Fat Separation and Derivatization Methods}

Fat separation was carried out according to ISO-IDF (2001) using n-pentane and diethyl ether after first adding an ammonium hydroxide solution to the milk. Milk fat separation was also carried out using the rapid method proposed by Feng et al. (2004). Thirty milliliters of raw milk was centrifuged at 17,800 $\times \mathrm{g}$ for $30 \mathrm{~min}$ at $4^{\circ} \mathrm{C}$ in a Beckman (Fullerton, CA) J2-MC centrifuge. The fat layer was transferred to a microtube and left at room temperature for approximately $30 \mathrm{~min}$ before being microcentrifuged at $19,300 \times g$ for $20 \mathrm{~min}$ at room temperature. After the second centrifugation, the top layer was removed for analysis.

Finally, milk fat separation was also carried out by the rapid method (Feng et al., 2004), but modifying the temperature of the first centrifugation. The refrigerated raw milk sample was tempered at $20^{\circ} \mathrm{C}$ for $20 \mathrm{~min}$, and centrifuged at $17,800 \times \mathrm{g}$ for $30 \mathrm{~min}$ at the same temperature. The fat layer was removed, transferred to microtubes, and centrifuged at $19,300 \times g$ again in the conditions mentioned in the previous paragraph.

For each method, separated lipids were stored in amber vials, exposed to a stream of $\mathrm{N}_{2}$, and frozen at $-20^{\circ} \mathrm{C}$ until analysis. In all cases, methyl esters of milk fat fatty acids were prepared by base-catalyzed methanolysis of the glycerides using $\mathrm{KOH}$ in methanol as described in ISO-IDF (2002).

\section{Gas Chromatography}

Fatty acid methyl esters were analyzed on a PerkinElmer chromatograph (model Clarus 500, Beaconsfield, UK) with a flame-ionization detector and autosampler. Fatty acids were separated using a CP-Sil 88 fusedsilica capillary column $(100 \mathrm{~m} \times 0.25 \mathrm{~mm}$ i.d. $\times 0.2 \mu \mathrm{m}$ film thickness, Chrompack, Middelburg, Netherlands). 
Table 2. Mean values and standard error mean (\% of total fatty acids) of fatty acids methyl esters of goats' milk determined by gas chromatography after fat separation by the reference method (ISO-IDF) and an alternative procedure based on a double centrifugation. ${ }^{1}$

\begin{tabular}{|c|c|c|c|c|c|}
\hline \multirow[b]{2}{*}{ Fatty acids } & \multicolumn{2}{|c|}{ Reference method } & \multicolumn{2}{|c|}{$\begin{array}{l}\text { Double centrifugation } \\
\text { method }\end{array}$} & \multirow{2}{*}{$\begin{array}{l}\text { Statistical } \\
\text { significance }\end{array}$} \\
\hline & Mean & SEM & Mean & SEM & \\
\hline $\mathrm{C} 4$ & 2.849 & 0.037 & 2.934 & 0.065 & NS \\
\hline $\mathrm{C} 6$ & 3.372 & 0.035 & 3.435 & 0.057 & NS \\
\hline $\mathrm{C} 8$ & 3.697 & 0.029 & 3.752 & 0.029 & NS \\
\hline C10 & 11.114 & 0.102 & 11.156 & 0.070 & NS \\
\hline C10:1 & 0.293 & 0.005 & 0.283 & 0.006 & NS \\
\hline C12 & 4.226 & 0.075 & 4.141 & 0.060 & NS \\
\hline anteiso $\mathrm{C} 13$ & 0.022 & 0.001 & 0.021 & 0.001 & NS \\
\hline $\mathrm{C} 13$ & 0.159 & 0.005 & 0.156 & 0.005 & NS \\
\hline isoC14 & 0.043 & 0.002 & 0.044 & 0.001 & NS \\
\hline C14 & 7.265 & 0.056 & 7.143 & 0.057 & NS \\
\hline isoC15 & 0.130 & 0.003 & 0.135 & 0.003 & NS \\
\hline anteiso $\mathrm{C} 15$ & 0.219 & 0.001 & 0.227 & 0.001 & $* * *$ \\
\hline C15 & 0.608 & 0.009 & 0.602 & 0.009 & NS \\
\hline C14:1 & 0.057 & 0.002 & 0.059 & 0.002 & NS \\
\hline isoC16 & 0.171 & 0.001 & 0.172 & 0.001 & NS \\
\hline C16 & 25.524 & 0.234 & 25.195 & 0.194 & NS \\
\hline isoC17 & 0.453 & 0.007 & 0.464 & 0.005 & NS \\
\hline anteisoC17 & 0.195 & 0.003 & 0.209 & 0.003 & $*$ \\
\hline C16:1 & 0.707 & 0.010 & 0.720 & 0.010 & NS \\
\hline C17 & 0.471 & 0.006 & 0.459 & 0.007 & NS \\
\hline C17:1 & 0.072 & 0.003 & 0.074 & 0.003 & NS \\
\hline C18 & 12.911 & 0.219 & 12.550 & 0.286 & NS \\
\hline C18:1 (4-11 trans) & 3.725 & 0.177 & 3.763 & 0.173 & NS \\
\hline $\mathrm{C} 18: 1$ cis -9 & 15.706 & 0.134 & 16.117 & 0.153 & $*$ \\
\hline C18:1 (other) & 0.800 & 0.036 & 0.804 & 0.042 & NS \\
\hline C18:2 (other) & 0.316 & 0.007 & 0.336 & 0.018 & NS \\
\hline C18:2 cis-9,cis-12 & 3.896 & 0.107 & 3.991 & 0.105 & NS \\
\hline $\mathrm{C} 20$ & 0.170 & 0.001 & 0.160 & 0.002 & $* * *$ \\
\hline C18:3 & 0.254 & 0.007 & 0.260 & 0.006 & NS \\
\hline C18:2 cis-9,trans -11 & 0.576 & 0.030 & 0.589 & 0.033 & NS \\
\hline
\end{tabular}

${ }^{1}$ Each separation method was repeated 4 times, and 2 column injections per separation were carried out for each of the 3 goats' milk samples.

${ }^{2} \mathrm{NS}=$ Not significant, $* P<0.05 ; * * * P<0.001$.

The column temperature was held at $70^{\circ} \mathrm{C}$ for $4 \mathrm{~min}$ after injection, increased at $13^{\circ} \mathrm{C} / \mathrm{min}$ to $175^{\circ} \mathrm{C}$, held at $175^{\circ} \mathrm{C}$ for $27 \mathrm{~min}$, increased at $4^{\circ} \mathrm{C} / \mathrm{min}$ to $215^{\circ} \mathrm{C}$, and held at $215^{\circ} \mathrm{C}$ for $36 \mathrm{~min}$. Helium was the carrier gas with a column inlet pressure of $207 \mathrm{kPa}$; and the injection volume was $0.2 \mu \mathrm{L}$. To obtain response factors, an anhydrous milk fat (reference material CRM-164) consisting of known amounts of fatty acids obtained from the European Commission (Brussels, Belgium) was used.

Each separation method was repeated 4 times, and 2 column injections per separation were carried out for each of the 3 ewe and goat milk samples. Ninety-six fatty acid profiles were therefore obtained.

Univariate variance analysis including repeated measures [one grouping factor (extraction method) and one trial factor (injection)] was carried out using an SPSS 13.0 XP system (SPSS Inc., Chicago, IL).

\section{RESULTS AND DISCUSSION}

Tables 1 and 2 show the fatty acid content of the ewe and goat milk samples determined after separating fat with the reference procedure (ISO-IDF, 2001) and the double centrifugation method used by Feng et al. (2004). Most of the fatty acids exhibited similar percentages in the different milk samples studied by both separation procedures, and statistical analysis revealed only small differences for some fatty acids. The results obtained were similar in both species of ruminants examined, in spite of the different physical characteristics and different lipid content in the milk fat. Theoretically, the creaming rate by centrifugation could be affected by several factors. For example, the total fat content, globule size, and their relative abundance could influence the viscosity of the milk and affect lipid separation. The creaming rate would be less in milk with the smallest fat globules. Some studies (Cerbulis et al., 1982; Attaie 
Table 3. Profile of fatty acid methyl esters of ewes' milk fat extracted by centrifugation at 4 and $20^{\circ} \mathrm{C}$ and analyzed by gas chromatography. ${ }^{1}$

\begin{tabular}{|c|c|c|}
\hline Fatty acid & $\begin{array}{l}\text { Centrifugation } \\
\text { at } 4^{\circ} \mathrm{C}\end{array}$ & $\begin{array}{l}\text { Centrifugation } \\
\text { at } 20^{\circ} \mathrm{C}\end{array}$ \\
\hline & \multicolumn{2}{|c|}{$\longrightarrow \%$ of total fatty acids -} \\
\hline C4 & $4.002 \pm 0.266$ & $4.014 \pm 0.253$ \\
\hline $\mathrm{C} 6$ & $3.388 \pm 0.214$ & $3.456 \pm 0.248$ \\
\hline $\mathrm{C} 8$ & $3.143 \pm 0.137$ & $3.082 \pm 0.122$ \\
\hline C10 & $9.234 \pm 0.226$ & $9.097 \pm 0.243$ \\
\hline C10:1 & $0.397 \pm 0.012$ & $0.391 \pm 0.013$ \\
\hline C12 & $4.650 \pm 0.048$ & $4.633 \pm 0.062$ \\
\hline anteisoC13 & $0.039 \pm 0.001$ & $0.039 \pm 0.001$ \\
\hline C13 & $0.200 \pm 0.002$ & $0.199 \pm 0.003$ \\
\hline isoC14 & $0.074 \pm 0.005$ & $0.075 \pm 0.008$ \\
\hline C14 & $10.383 \pm 0.071$ & $10.395 \pm 0.073$ \\
\hline isoC15 & $0.157 \pm 0.005$ & $0.156 \pm 0.003$ \\
\hline anteisoC15 & $0.349 \pm 0.004$ & $0.347 \pm 0.003$ \\
\hline C15 & $0.854 \pm 0.006$ & $0.852 \pm 0.007$ \\
\hline C14:1 & $0.166 \pm 0.003$ & $0.166 \pm 0.002$ \\
\hline isoC16 & $0.247 \pm 0.002$ & $0.247 \pm 0.002$ \\
\hline C16 & $25.014 \pm 0.268$ & $25.109 \pm 0.292$ \\
\hline isoC17 & $0.468 \pm 0.005$ & $0.467 \pm 0.005$ \\
\hline anteisoC17 & $0.269 \pm 0.013$ & $0.278 \pm 0.018$ \\
\hline C16:1 & $1.354 \pm 0.023$ & $1.346 \pm 0.032$ \\
\hline C17 & $0.636 \pm 0.009$ & $0.639 \pm 0.009$ \\
\hline C17:1 & $0.221 \pm 0.004$ & $0.220 \pm 0.003$ \\
\hline C18 & $7.513 \pm 0.128$ & $7.534 \pm 0.157$ \\
\hline C18:1 (4-11 trans) & $3.864 \pm 0.052$ & $3.852 \pm 0.036$ \\
\hline C18:1 cis-9 & $18.538 \pm 0.341$ & $18.589 \pm 0.304$ \\
\hline C18:1 (other) & $0.842 \pm 0.026$ & $0.838 \pm 0.010$ \\
\hline C18:2 (other) & $0.339 \pm 0.010$ & $0.340 \pm 0.006$ \\
\hline C18:2 cis-9,cis-12 & $2.369 \pm 0.035$ & $2.370 \pm 0.017$ \\
\hline $\mathrm{C} 20$ & $0.165 \pm 0.006$ & $0.166 \pm 0.003$ \\
\hline C18:3 & $0.318 \pm 0.006$ & $0.318 \pm 0.003$ \\
\hline C18:2 cis-9,trans-11 & $0.788 \pm 0.021$ & $0.791 \pm 0.007$ \\
\hline
\end{tabular}

${ }^{1}$ Values correspond to the means $( \pm \mathrm{SD})$ of 6 independent fat separations and 2 injections per separation.

and Richter, 2000) determined the fat globule size distribution in different ruminants and found that the average fat globule size is smallest in goat's milk. Mehaia (1995) reported the following order of decreasing globule size: cow > ewe > goat, thereby confirming previous research (Anifantakis, 1986; Juárez and Ramos, 1986). Additionally, bovine milk creams more rapidly than goat's milk because of agglutination, which causes clustering of the fat globules. Agglutinin is apparently absent in goat's milk.

To check the effect of the separation temperature on the fatty acid profile, the procedure used by Feng et al. (2004) was modified and the first centrifugation was done at room temperature $\left(20^{\circ} \mathrm{C}\right)$. Theoretically, less viscosity resulting from the increase in temperature should facilitate the extraction of the lipid phase in the centrifugal separation of milk (Walstra, 1995). The proportion of the different fatty acids in ewe milk fat extracted 6 times at each of the 2 temperatures is shown in Table 3. There are no significant differences in the results of these 2 procedures for any fatty acid. This indicates that the method could be carried out just as easily at room temperature.

The coefficient of variation for the different fatty acids that can be extracted from the data in Table 3 mean that it is possible to examine the precision of the new analysis method. Most of the fatty acid coefficients of variation were less than $3 \%$, and the repeatability of the analyses was similar when the fat separation was done at either temperature. The least precision was observed in determining the short-chain fatty acids (C4-C6-C8), where the coefficients of variation for these compounds were between 3 and $7 \%$. This finding could be attributed to the greater volatility of these fatty acids, which means that they are lost during the methylation process. This loss, calculated by Feng et al. (2004), was around $20 \%$.

To summarize, the separation procedure proposed by Feng et al. (2004) and modified in our laboratory, followed by the reference derivatization method (ISOIDF, 2002), can be useful for routinely determining the milk fatty acid profile of different ruminants. The method's applicability to milk fats with different characteristics was demonstrated in our study. Although the fatty acid profile showed significant differences for some fatty acids compared with the profile obtained using the reference extraction method (ISO-IDF, 2001), these differences were small and the method could be applied in studies monitoring the evolution of the content of these components.

\section{ACKNOWLEDGMENTS}

The authors are grateful to the Ministerio de Ciencia y Tecnología (project AGL2002-00887) for financing this project. The authors are indebted to Laura Barrios for her assistance with the statistical analysis.

\section{REFERENCES}

Anifantakis, E. M. 1986. Comparison of the physico-chemical properties of ewes' and cows' milk. Bull. Int. Dairy Fed. 202:42-53.

Attaie, R., and R. L. Richter. 2000. Size distribution of fat globules in goat milk. J. Dairy Sci. 83:940-944.

Cerbulis, J., O. W. Parks, and H. M. Farrell. 1982. Composition and distribution of lipids of goats milk. J. Dairy Sci. 65:2301-2307.

Feng, S., A. L. Lock, and P. C. Garnsworthy. 2004. A rapid method for determining fatty acid composition of milk. J. Dairy Sci. 87:3785-3788.

Fontecha, J., V. Díaz, M. J. Fraga, and M. Juárez. 1998. Triglyceride analysis by gas chromatography in assessment of authenticity of goat milk fat. J. Am. Oil Chem. Soc. 75:1893-1896.

Juárez, M., and M. Ramos. 1986. Physico-chemical characteristics of goat's milk as distinct from those of cow's milk. Bull. Int. Dairy Fed. 202:54-57.

Hara, A., and N. S. Radin. 1978. Lipid extraction of tissues with a low-toxicity solvent. Anal. Biochem. 90:420-426.

ISO-IDF. 2001. Milk and milk products-Extraction methods for lipids and liposoluble compounds. International Standard ISO 
14156-IDF 172:2001. International Dairy Federation, Brussels, Belgium.

ISO-IDF. 2002. Milk fat-Preparation of fatty acid methyl esters. International Standard ISO 15884-IDF 182:2002. International Dairy Federation, Brussels, Belgium.

Lucas, A., J. A. H. Gibbs, R. L. J. Lyster, and J. D. Baum. 1978. Creamatocrit: Simple clinical technique for estimating fat concentration and energy value of human milk. Br. Med. J. 1:1018-1020.

Mehaia, M. A. 1995. The fat globule size distribution in camel, goat, ewe and cow milk. Milchwissenschaft 50:260-263.
Sukhija, P. S., and D. L. Palmquist. 1988. Rapid method for determination of total fatty acid content and composition of feedstuffs and feces. J. Agric. Food Chem. 36:1202-1206.

Verheul, F. E. A. M., M. J. A. van den Bosch, P. J. H. C. Cornelissen, and J. J. J. Waelkens. 1986. Simplified and rapid methods for the determination of protein, fat and lactose in human milk and the energy intake by the breast-fed infant. J. Clin. Chem. Clin. Biochem. 24:341-346.

Walstra, P. 1995. Physical chemistry of milk fat globules. Pages 131178 in Advanced Dairy Chemistry, Lipids. Vol. 2. P. F. Fox, ed. Chapman and Hall, London, UK. 